Supporting Information

\title{
End group modification for black phosphorus: simultaneous improvement of chemical stability and gas sensing performance
}

Yanling Xu $u^{a}$, Xiaofang Lib $i^{b}$, Yangyang Song ${ }^{a}$, Ruiguang Zhang ${ }^{a}$, Wenjing Yuan ${ }^{* a}$, Dan $X^{*}{ }^{* a}$, Qingzhong Xue $e^{* b}$, Fuxing Yin ${ }^{* a}$

E-mail: ywj11@tsinghua.org.cn

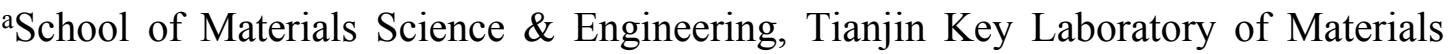
Laminating Fabrication and Interface Control Technology, Hebei University of Technology, Tianjin 300130, China.

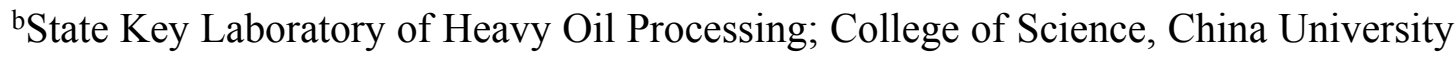
of Petroleum, Qingdao 266580, Shandong, China 


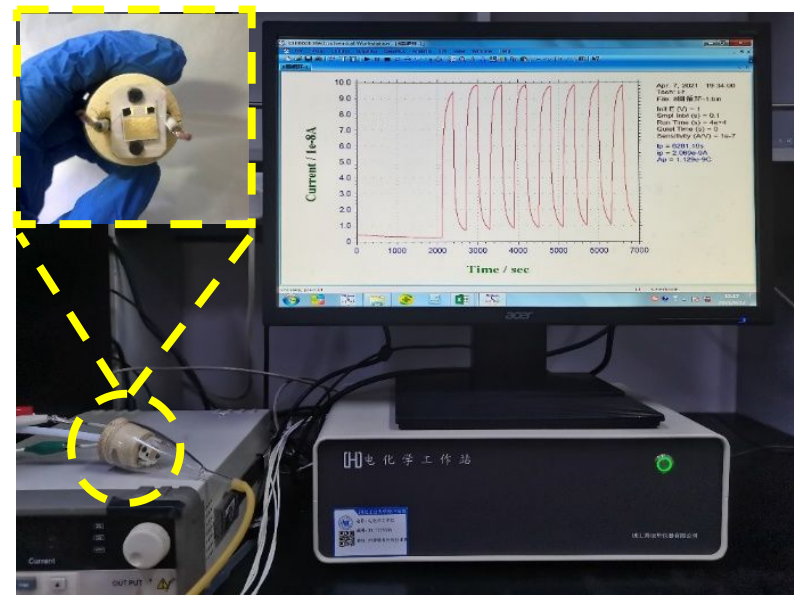

Figure S1. Digital image of the sensing system including the sensor, the chamber and the electrochemical analyzer.

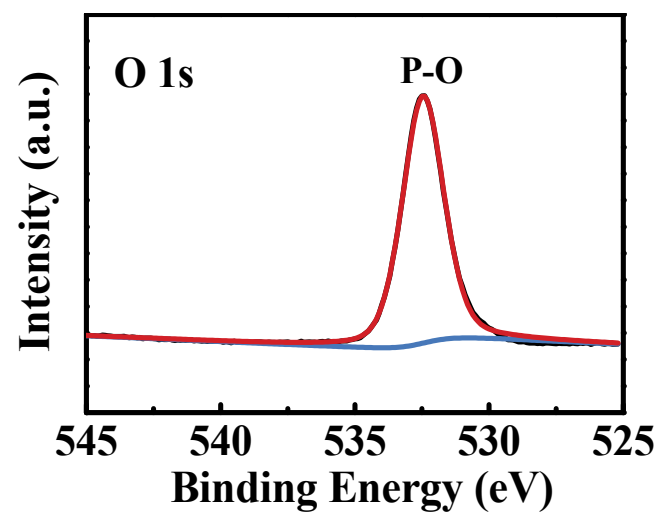

Figure S2. High-resolution XPS O1s spectrum of BP.
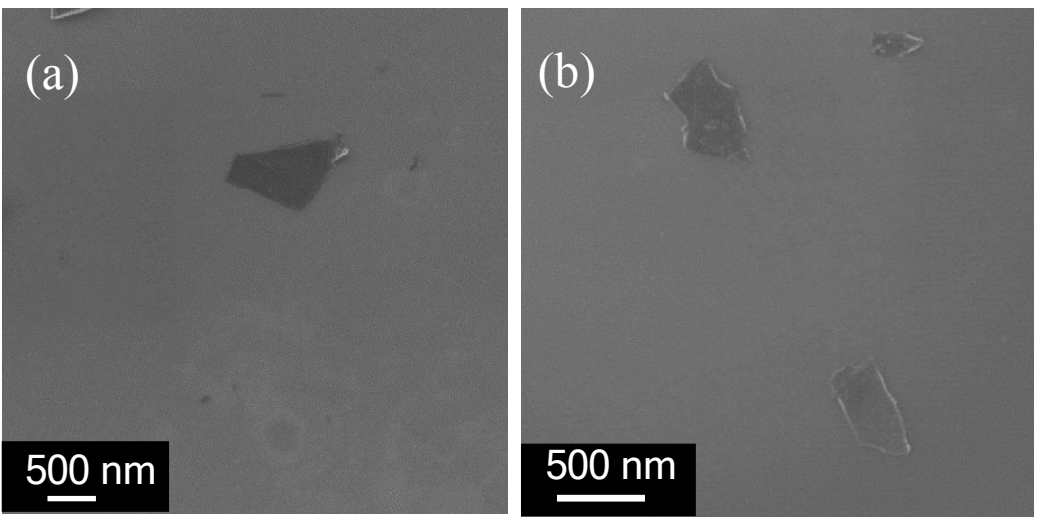

Figure S3. SEM image of (a) BP nanosheets and (b) F-BP nanosheets. 
(a)

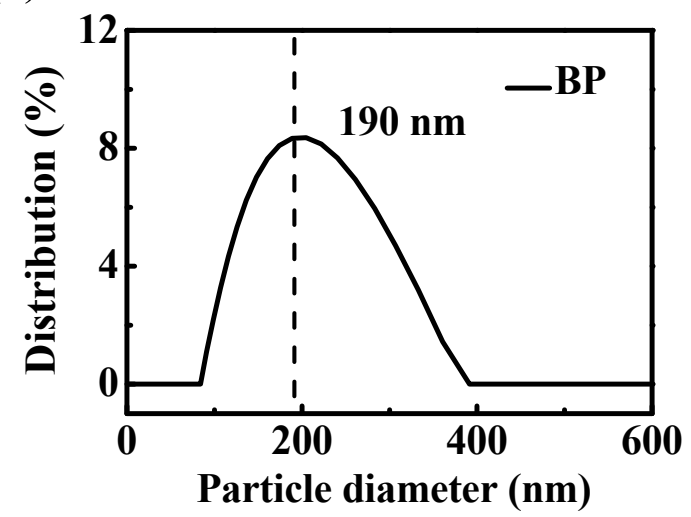

(b)

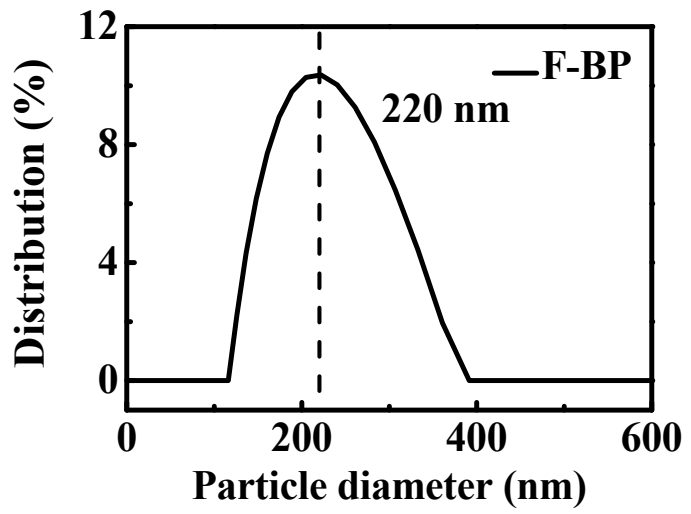

Figure S4. Particle size distribution of (a) BP nanosheets and (b) F-BP nanosheets.

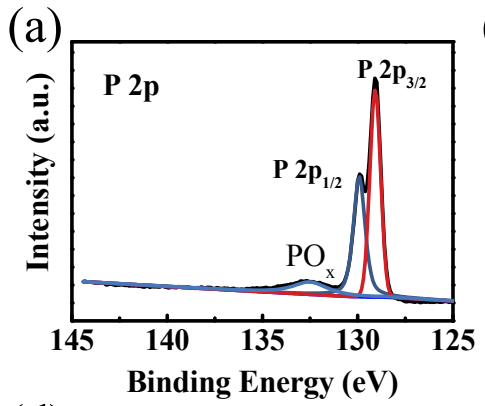

(d)

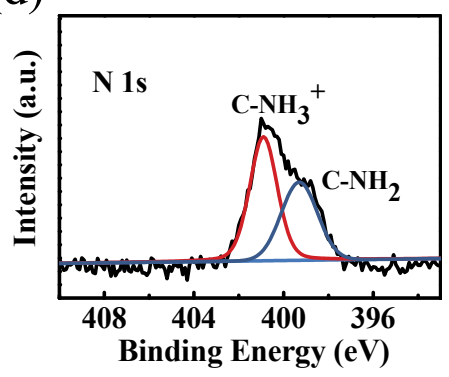

(b)

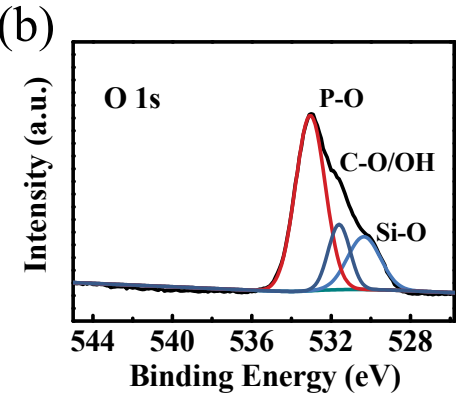

(e)

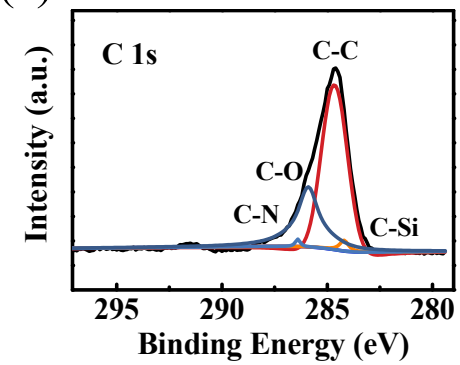

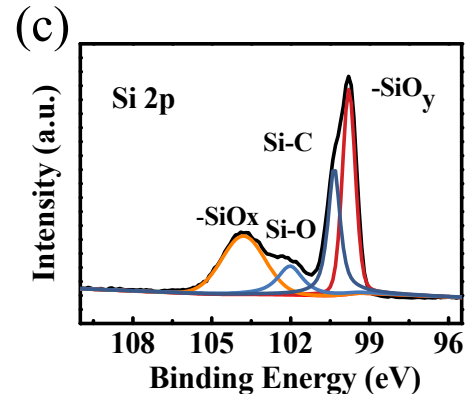

Figure S5. High-resolution XPS P2p (a), O1s (b), Si 2p (c), N1s (d), and C1s (e) spectrum of APTES-BP. The XPS spectra confirmed the successfully grafting of APTES moieties onto BP nanosheets. 
(a)

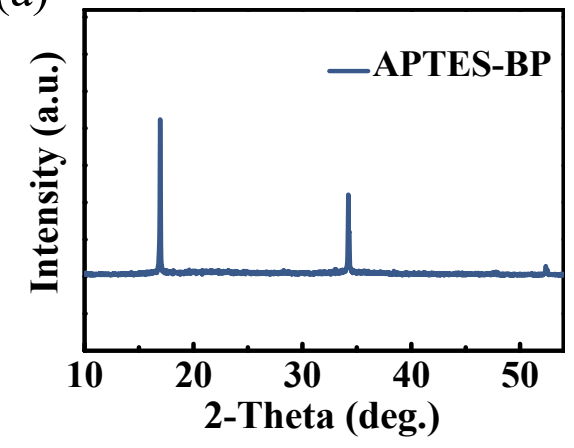

(b)

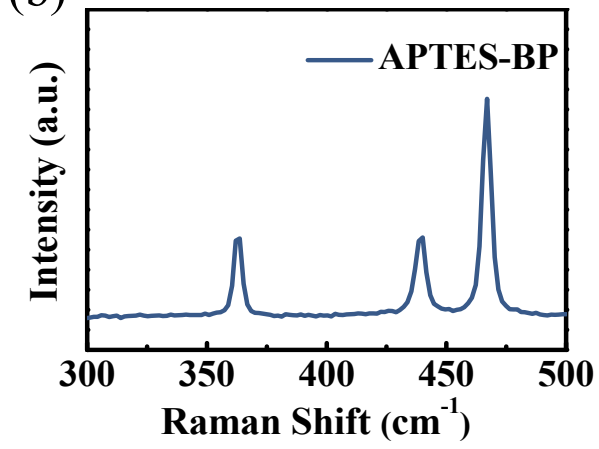

Figure S6. (a) XRD pattern and (b) Raman spectrum of APTES-BP. The XRD diffraction peaks of APTES-BP are the same with those of pristine BP, indicating no crystallinity variation after functionalization. Raman spectra of APTES-BP display three characteristic Raman signals at 360,437 , and $465 \mathrm{~cm}^{-1}$, assigned to $\mathrm{A}_{\mathrm{g}}{ }_{\mathrm{g}}, \mathrm{B}_{\mathrm{g}}{ }_{\mathrm{g}}$, and $\mathrm{A}_{\mathrm{g}}^{2}$ modes, respectively.

(a)

(b)

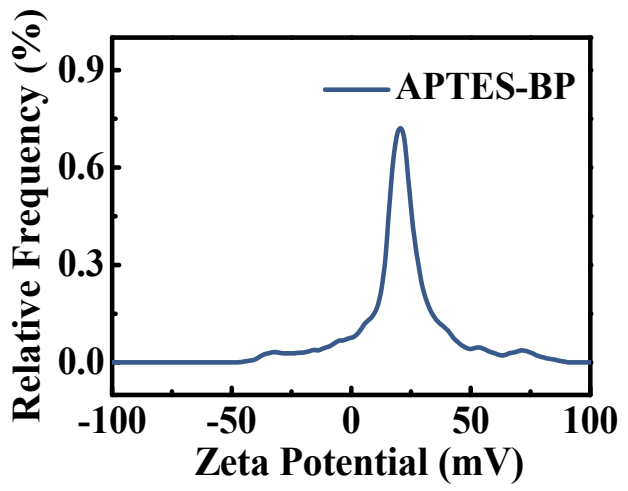

Figure S7 (a) Water contact angle of the APTES-BP assembled film. (b) Zeta potential of APTES-BP nanosheets. Zeta potential of APTES-BP nanosheets is positive due to the existence of $-\mathrm{NH}_{2}$ groups. 


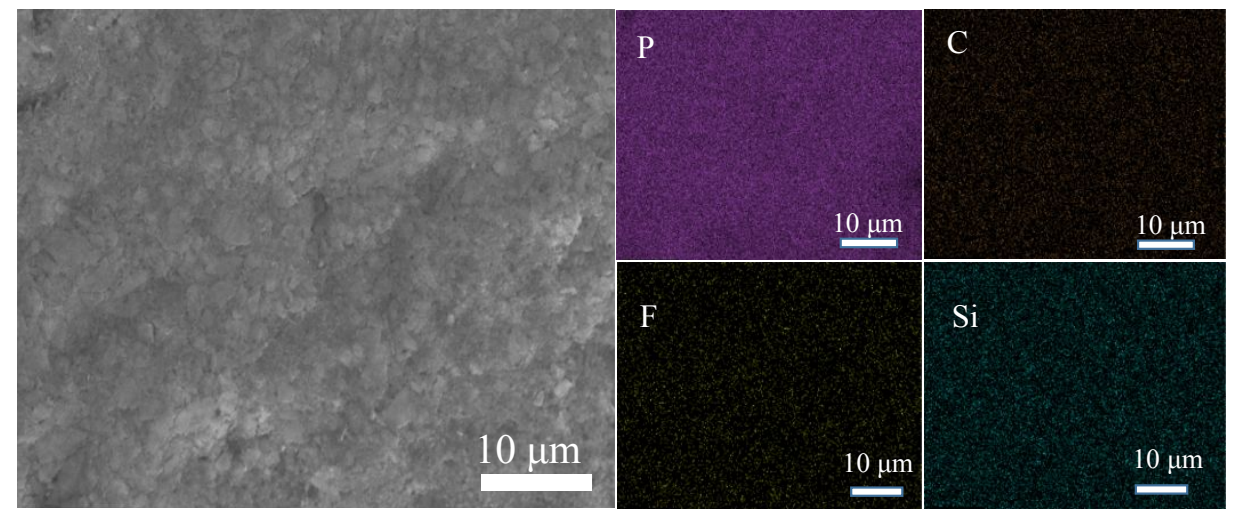

Figure S8. SEM image of an assembled F-BP sensing film and corresponding elemental mapping images.

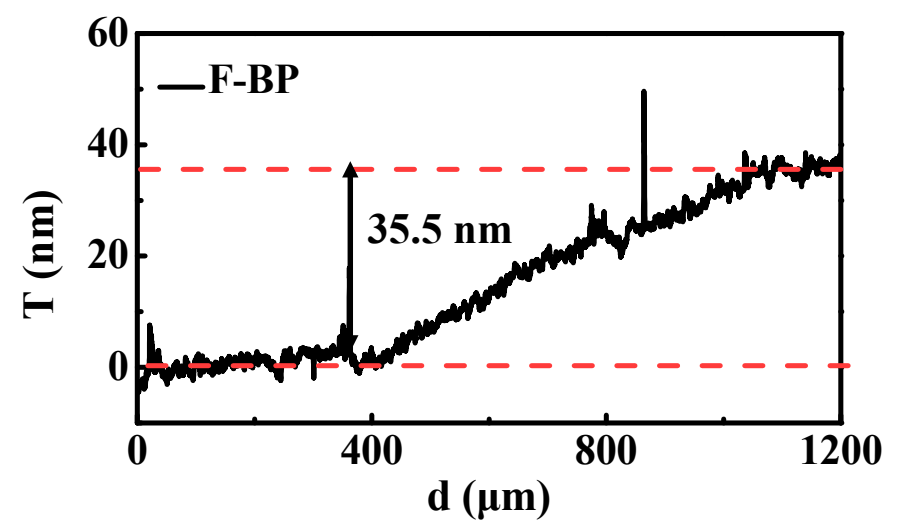

Figure S9. Thickness of the sensing layer deposited onto an IE. 

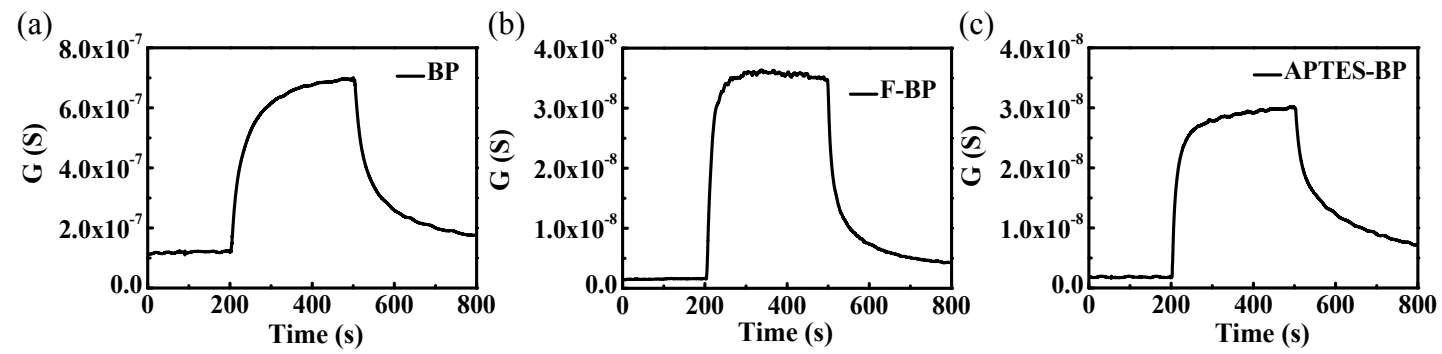

Figure S10. Transient conductivity variation of the BP (a), F-BP (b) and APTES-BP (c) sensors to $1 \mathrm{ppm}$ of $\mathrm{NO}_{2}$.

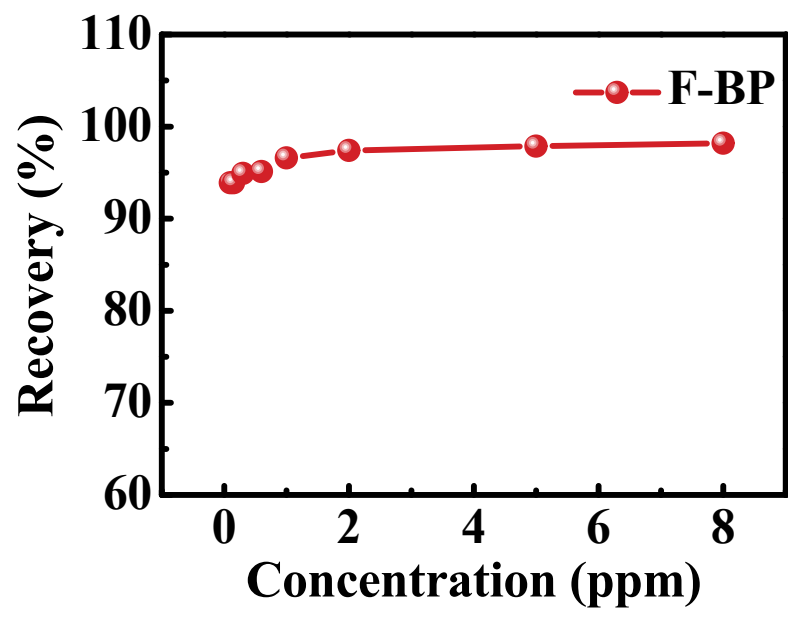

Figure S11. Recovery property of the F-BP sensor during the multi-cycle sensing tests.

The percent recovery of the sensor is defined as Recovery $(\%)=\left(G-G_{r}\right) /\left(G-G_{0}\right) \times 100 \%$, where $G_{0}$ is the conductance in $\mathrm{N}_{2}$ before introduction of $\mathrm{NO}_{2}, G$ is the maximal conductance in $\mathrm{NO}_{2}$, and $G_{r}$ is the recovery conductance after purging with $\mathrm{N}_{2}$. 


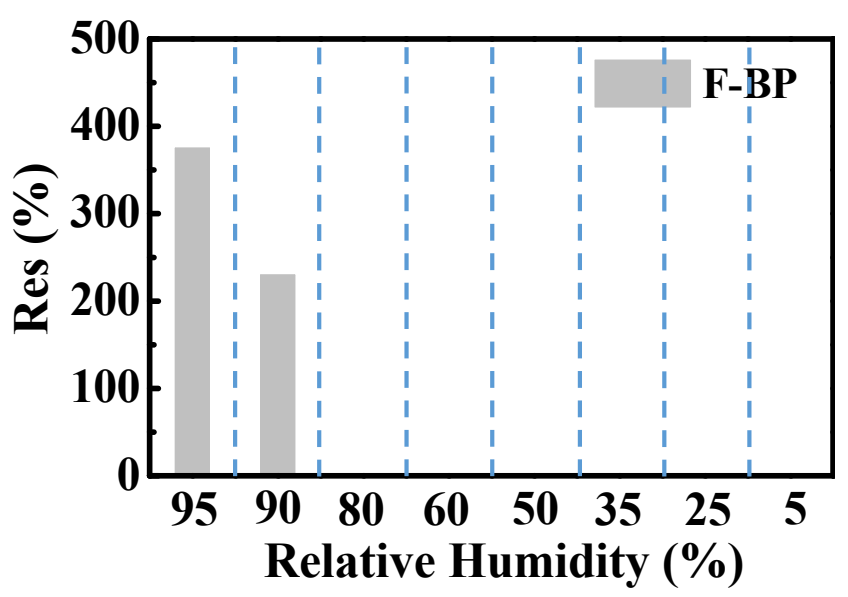

Figure S12. Response intensity of the F-BP sensor to water vapor.

(a)

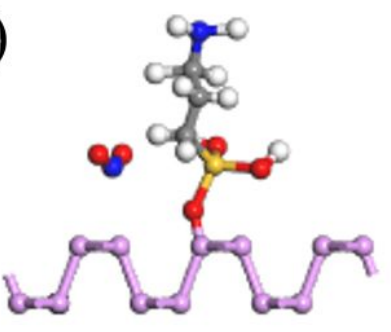

(b)

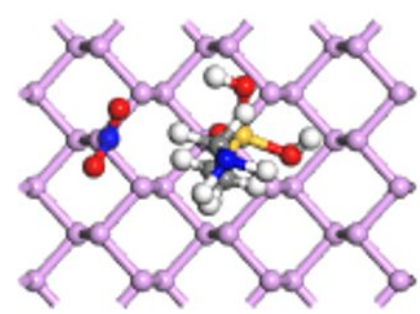

Figure S13. (a) Side and (b) top views of minimum energy configurations for an $\mathrm{NO}_{2}$ molecule adsorbed on APTES-BP surface.

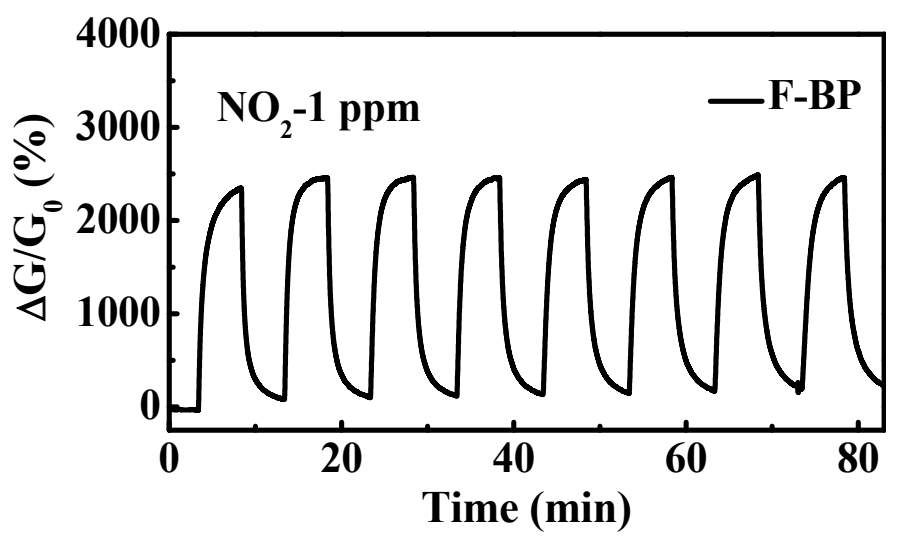

Figure S14. Sensing response of the F-BP sensor toward $1 \mathrm{ppm}$ of $\mathrm{NO}_{2}$ during multicycle tests. 
(a)

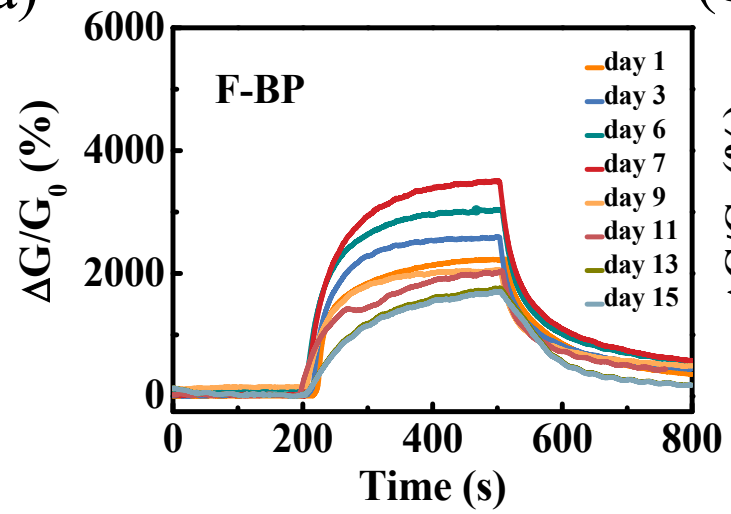

(b)

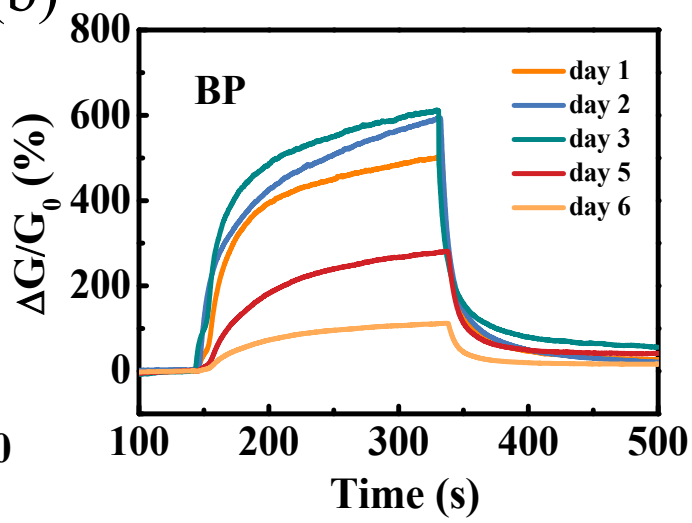

Figure S15. Real-time sensing responses of the F-BP sensor (a) and pristine BP sensor (b) during storage in air for different time periods.

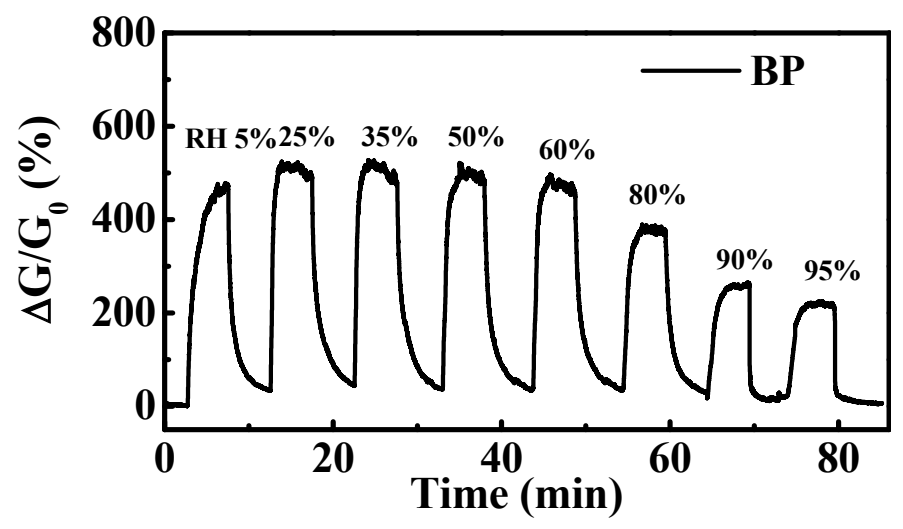

Figure S16. Sensing performance of the pristine BP sensor at $1 \mathrm{ppm}$ of $\mathrm{NO}_{2}$ in humid environment with $\mathrm{RH}$ ranging from 5 to $95 \%$. 
Table S1. Sensing performance of various 2D nanomaterials and their composites toward $\mathrm{NO}_{2}$ (performed at room-temperature)

\begin{tabular}{|c|c|c|c|c|c|c|c|}
\hline Materials ${ }^{a}$ & $\begin{array}{c}\mathrm{NO}_{2} \\
(\mathrm{ppm})\end{array}$ & $\begin{array}{l}\text { Sensitivity } \\
\text { (Response) }\end{array}$ & $\begin{array}{l}\text { Experimental } \\
\text { LoD (ppb) }\end{array}$ & $\begin{array}{c}\text { Response/ } \\
\text { recover time } \\
\text { (min) }\end{array}$ & $\begin{array}{c}\text { Sufficient } \\
\text { recovery }\end{array}$ & Targets & Ref. \\
\hline F-BP & 1 & $2358 \%$ & 40 & $0.7 / 1.7$ & $\begin{array}{c}\text { Yes } \\
(93-100 \%)\end{array}$ & $\mathrm{NO}_{2}, \mathrm{H}_{2} \mathrm{O}$ & $\begin{array}{r}\text { This } \\
\text { work }\end{array}$ \\
\hline BP nanosheets & 0.04 & $16 \%$ & 5 & $5 / 10$ & No & $\mathrm{NO}_{2}$ & 1 \\
\hline BP nanosheets & 1 & $40 \%$ & 20 & $\mathrm{nr}$ & Yes & $\mathrm{NO}_{2}, \mathrm{NH}_{3}, \mathrm{H}_{2}$ & 2 \\
\hline $\begin{array}{l}\text { BP size } \\
\text { distribution } \\
(\approx 400 \mathrm{~nm})\end{array}$ & 0.1 & $67 \%$ & 100 & $1.25 / 10$ & No & $\mathrm{NO}_{2}$ & 3 \\
\hline $\begin{array}{l}\text { size-controlled } \\
\text { BP }\end{array}$ & 1 & $\sim 400 \%$ & 80 & $4.8 / 6.2$ & Yes & $\mathrm{NO}_{2}, \mathrm{NH}_{3}$ & 4 \\
\hline AQNW-BP & 1 & $570 \%$ & 50 & $2-5 / 0.6-3.7$ & No (55 95\%) & $\mathrm{NO}_{2}, \mathrm{NH}_{3}$ & 5 \\
\hline $\begin{array}{l}\mathrm{BP} / \text { benzyl } \\
\text { viologen }\end{array}$ & 0.05 & $33 \%$ & 25 & $\mathrm{nr} />60$ & Yes $(95 \%)$ & $\mathrm{NO}_{2}, \mathrm{NH}_{3}$ & 6 \\
\hline $\mathrm{MoS}_{2}$ & 100 & $180 \%$ & 100000 & $3 / 10$ & No & $\mathrm{NO}_{2}, \mathrm{NH}_{3}$ & 7 \\
\hline $\mathrm{MoS}_{2}-\mathrm{PtNPs}$ & 1.2 & 11.5 & 500 & $\sim 30 / \sim 60$ & Yes & $\mathrm{NO}_{2}$ & 8 \\
\hline $\mathrm{MoS}_{2} / \mathrm{PbS}$ & 5 & $7 \%$ & 5000 & $0.5 / 3.9$ & Yes & $\begin{array}{c}\mathrm{NO}_{2}, \mathrm{NH}_{3}, \\
\mathrm{CH}_{3} \mathrm{OH}\end{array}$ & 9 \\
\hline $\begin{array}{l}\text { AgNP/3D- } \\
\text { AQRGO }\end{array}$ & 1 & 10.3 & 20 & $5 / 10$ & Yes $(\sim 90 \%)$ & $\mathrm{NO}_{2}$ & 10 \\
\hline Porous RGO & 1 & 2.44 & 20 & $10 / 15$ & $\begin{array}{l}\text { Yes } \\
(90 \sim 100 \%)\end{array}$ & $\begin{array}{c}\mathrm{NO}_{2}, \mathrm{NO} \\
\mathrm{NH}_{3}\end{array}$ & 11 \\
\hline
\end{tabular}

a Abbreviations: $\mathrm{nr}=$ not reported

\section{Reference}

(1) A. N. Abbas, B. Liu, L. Chen, Y. Ma, S. Cong, N. Aroonyadet, M. Koepf, T. Nilges, C. Zhou, ACS Nano 2015, 9, 5618.

(2) M. Donarelli, L. Ottaviano, L. Giancaterini, G. Fioravanti, F. Perrozzi, C. Cantalini, 2D Mater. 
2016, 3, 025002.

(3) S.-Y. Cho, Y. Lee, H.-J. Koh, H. Jung, J.-S. Kim, H.-W. Yoo, J. Kim, H.-T. Jung, Adv. Mater. $2016,28,7020$.

(4) T. Chen, Z. Cheng, Q. Tian, J. Wang, X. Yu, D. Ho, ACS Appl. Nano Mater. 2020, 3, 6440.

(5) W. Yuan, Y. Tang, K. Yang, Z. Hua, F. Yin, D. Xia, Chem. Eng. J. 2020, 394, 124933.

(6) H. Ren, Y. Zhou, Y. Wang, X. Zhu, C. Gao, Y. CGuo, Sens. Actuators B Chem. 2020, 321, 128520.

(7) D. J. Late, Y.-K. Huang, B. Liu, J. Acharya, S. N. Shirodkar, J. Luo, A. Yan, D. Charles, U. V. Waghmare, V. P. Dravid, C. N. R. Rao, ACS Nano 2013, 7, 4879.

(8) D. H. Baek, J. Kim, Sens. Actuators B Chem 2017, 250, 686.

(9) X. Xin, Y. Zhang, X. Guan, J. Cao, W. Li, X. Long, X. Tan, ACS Appl. Mater. Interfaces 2019, $11,9438$.

(10) F. Li, H. Peng, D. Xia, J. Yang, K. Yang, F. Yin, W. Yuan, ACS Appl. Mater. Interfaces 2019, $11,9309$.

(11) H. Peng, F. Li, Z. Hua, K. Yang, F. Yin, W. Yuan, Sens. Actuators B 2018, 275, 78. 